\title{
An Advanced Energy Management Framework to Promote Energy Awareness
}

\author{
Konstantin Vikhorev*, Richard Greenough, Neil Brown \\ Institute of Energy and Sustainable Development, De Montfort University, Leicester, LE1 9BH, United Kingdom
}

\begin{abstract}
Increasing energy costs, new environmental legislation, and concerns over energy security are driving efforts to increase industrial energy efficiency across the European Union and the world. Manufacturers are keen to identify the most cost-effective techniques to increase energy efficiency in their factories. To achieve the desired efficiency improvements, energy use should be measured in more detail and in real-time, to derive an awareness of the energy use patterns of every part of the manufacturing system. In this paper, we propose a framework for energy monitoring and management in the factory. This will allow decision support systems and enterprise services to take into consideration the energy used by each individual productive asset and related energy using processes, to facilitate both global and local energy optimization. The proposed framework incorporates standards for energy data exchange, on-line energy data analysis, performance measurement and display of energy usage.
\end{abstract}

Keywords: Energy management, Sustainable manufacturing, Data Stream Analysis, Complex Event Processing

\section{Introduction}

Energy is an abstract concept. We cannot see it or measure it directly, yet we know that it has value because of the work that it can do and because energy carriers such as electricity and gas are expensive. Although we speak of energy consumption, we know that from a thermodynamics perspective it cannot be consumed, merely converted from one form to another and that such conversions inevitably incur a loss of value. The generation of electrical energy by combustion harms our environment through the emission of greenhouse gases, and the cost of energy carriers is rising. It is therefore important that industries become more energy efficient for the sake of their competitiveness and the global environment.

The global industrial sector used approximately 98 EJ of energy in 2008 and this is projected to increase by $44 \%$ between 2006 and 2030. European energy use was 48.5 EJ in 2008, of which the industrial sector used 13.5 EJ (IEA, 2010). Industrial $\mathrm{CO}_{2}$ emissions are driven by the amount and type of energy used by factories as well as indirect emissions from electricity production. Between 1990 and 2005, global $\mathrm{CO}_{2}$ emissions from final energy use increased to $21.2 \mathrm{Gt} \mathrm{CO}_{2}$ of which manufacturing industry is responsible for the biggest share at $38 \%$ (IEA, 2007, 2008b).

The development of sustainable industry (Evans et al., 2009) is essential for the transition of developed nations towards low carbon economies and clearly energy can no longer be considered a fixed operational expense, and instead must be treated as a resource to be managed alongside materials, cash and the workforce. Energy management is becoming an essential as-

\footnotetext{
${ }^{*}$ Corresponding author.

Email address: kvikhorev@dmu. ac.uk (Konstantin Vikhorev)
}

pect of operations management for producers and it is now supported by international standards (e.g., BSi, 2009, ISO, 2011). It is also a concern for customers, since it affects their Scope 3 emissions (WRI, 2009). Original Equipment Manufacturers (OEMs) are under pressure to demonstrate how each stage of the supply chain is operated sustainably, and energy management plays a vital role in this. To audit a product's carbon footprint, a manufacturer must be able to trace the emissions produced during each components manufacture along the entire supply chain. This requires detailed knowledge of the energy used by each process and how this can be assigned to specific products. Failure to develop information systems to facilitate such analysis may cost manufacturers through carbon taxes, excessive energy use, and possibly also affecting their corporate image.

Effective industrial energy management is often very context specific, since it depends on many local factors such as product design, process choice, national fuel mix, etc. This means that it can be difficult to replicate energy saving solutions derived from one industry in a different industrial sector and/or location. In this respect energy management differs significantly from quality management, although the ISO standards share many similarities such as the 'plan, do, check, act' cycle. Energy management therefore requires a flexible approach, but it will benefit from a framework within which good practice can be established. The framework for advanced energy management described in this paper will allow energy managers at all levels to identify the patterns of energy use at different levels of analysis in their factory and thus make meaningful decisions based on performance indicators that are relevant to them. 


\subsection{Research Focus}

The focus of the research described in this paper is the feedback of energy usage information in real-time to facilitate action by those responsible for industrial processes. This feedback is intended to foster an awareness of process energy use in the same way that domestic energy monitors are intended to increase energy awareness (i.e., understanding of energy use) in the home. Domestic energy monitors usually display electrical energy data only and these data are aggregated at dwelling level, making it difficult to compare historical energy use by different devices. Signal processing techniques have been applied to separate and display the energy used by individual domestic devices (Hart, 1992, Patel et al., 2007). There is no such equivalent for industrial processes, although in many facilities sub-metering and half-hourly reporting facilitate energy management at a departmental and facility level. Studies of household energy use have identified energy savings of over $20 \%$ simply by providing energy information through monitoring (Darby, 2006, Hargreaves et al., 2010, Lertlakkhanakul et al., 2010, Meyers et al., 2010).

Industrial energy management has many similarities with quality management, as can be seen by comparing the energy management standard ISO 50001 (ISO, 2011) and the quality management standard ISO 9001 (ISO, 2008). Quality managers understand the importance of developing a 'quality culture' on the factory floor and this is fostered by display of quality related information such as such as defect rates, process control charts and overall equipment effectiveness. Conventional energy management methods at the factory floor are limited because the energy performance of individual processes cannot be understood without continuous measurement of energy consumption and an infrastructure to map process energy data onto relevant business performance measures. This lack of insight (which we can call 'energy awareness') limits the scope for timely decisions to reduce energy use.

The research question that arises in this context is: "How might the presentation of real-time energy information at the process level reduce the energy used in production?" This research question is based on two assumptions: 1) that the presentation of suitable decision support information at the shop floor will allow operators to save energy by temporarily shutting down a process that has excess short-term capacity; and 2) that operators will be given the training, authority and motivation to make process shut-down decisions. The human behavioural aspects of this question will be the subject of a future paper. This paper describes an advanced energy management framework and a prototype information system.

\section{Methodology}

Two methodological approaches are relevant for this paper: an action research (AR) framework (Greenwood, 1999) and case study research (Yin, 2008). The overall research is embedded into AR framework to ensure a structured research process and its continual improvement. Case study research was applied as the main source of data collection and to test research hypothesis within its real-life context. In order to address the research question above, the following four steps were adopted:

\section{State-of-the-art analysis}

Literature was reviewed on existing energy management systems, international energy standards used in manufacturing, performance measures, and visual interface design. A comprehensive overview of the required elements of an energy management framework was generated.

\section{Energy survey}

A preliminary energy survey was conducted at the premises of a major European automotive manufacturer in order to identify the relative proportions of energy losses and saving potential. It involved minimal interviews with site-operating personnel, energy measurements and a review of facility utility bills and other operating data, and a walk-through of the facility to become familiar with the building and equipment operation.

\section{Design \& Implementation}

Based on results the state of the art analysis, the requirements for an advanced energy management framework were identified, including data standards and data processing, key performance indicators, and graphical user interface elements.

\section{Evaluation}

The framework is currently being deployed via a prototype information system situated on a machining line at the case study facility. The case study will used to evaluate the deployed system and the energy management framework by comparing the energy consumption of each production asset before and after system deployment. The nature of the energy decision process used by the factory personnel will also be analysed. The qualitative results of the evaluation are presented.

\section{Elements of Industrial Energy Management}

One cannot manage what one does not measure, so data collection is fundamental to energy management. Industrial energy data are collected at all levels of granularity from the subprocess level to the global industry sector and at different temporal levels from milliseconds to yearly, depending on the nature of the analysis to be performed. At the industry sector level, organisations such as International Energy Agency (IEA) collect, analyse, and disseminate energy information. At a company level, organisations carry out energy audits to understand energy flows in buildings, manufacturing systems or processes and thus reduce the amount of energy used without negatively affecting productivity. However energy management goes beyond energy monitoring and targeting; the deep integration between the factory floor and factory building must be understood. Energy data gathered from all layers of an organisation need to be correlated and evaluated together to develop holistic energy efficiency strategies (Karnouskos et al., 2009). The most significant energy consumers, be they electrical, thermal, chemical or mechanical (e.g. compressed air) need to be identified, monitored and analysed in real-time to increase industrial energy 
efficiency. This requires standardisation of data collection, online data processing and visualisation techniques.

\subsection{Energy Data Standards}

For the sake of accurate and meaningful analysis, standards should be defined and applied at each level of the organisation at which energy data are collected. An energy data standard specifies the way that information is to be derived from the data, and how the energy information is to be processed and stored. The standard includes the definition of the sampling period, data precision, units, descriptions, etc.

A recently defined standard for industrial data is MTConnect (MTConnect, 2010). This is used to monitor machine tools and it includes a specification for machine tool energy data. It defines a common language and structure for communication between manufacturing equipment, and allows access to manufacturing data using standardised interfaces. However, this standard is only intended to simplify data exchange between controls, devices and software applications using Internet protocol, and it does not provide any requirements for data transfer (e.g., the type of data, sampling rates, units etc.). Kara et al. (2011) describe an approach to the monitoring of electrical power within manufacturing. In their system, electricity consumers are classified according to three levels: the factory, department, and unit process. Each level has a specific set of technical requirements for the metering equipment and the monitoring system (e.g., measurement resolution, standards, and parameters). However, this approach cannot be applied to other energy carriers used in industry, such as gas, steam, water or compressed air.

\subsection{Performance measures}

To improve energy efficiency an organization must adopt a procedure of monitoring and targeting (BSi, 2009, ISO, 2011, Kannan and Boie, 2003). Monitoring requires knowledge of current energy use, according to a set of key performance indicators (KPIs) that are relevant to the energy using processes employed. Targeting refers to the desired reduction of energy usage, for example a certain percentage reduction over a given period.

\subsubsection{Energy Performance Indicators}

Performance measures for energy efficiency are a subset of those related to industrial performance as a whole. In general, energy performance measures are designed to measure how much benefit is derived from specific energy use. An energy performance indicator can be compared against an internal target, or an external benchmark to give an indication of performance (Ahmad and Dhafr, 2002). Many of the indicators are simple ratios of the output of an activity to the energy used to carry out that activity (e.g., specific energy consumption (SEC) - the ratio of energy consumption to units). Energy related indicators enable actors within an organisation to react to negative developments and to identify improvement opportunities. Analysis of historical data allows the processes in the company to be assessed and measures to be developed that positively influence developments in the future. Energy data can be measured and energy performance derived at different levels within the organisation, with appropriate measures being applied at each level, as shown in Figure 1.

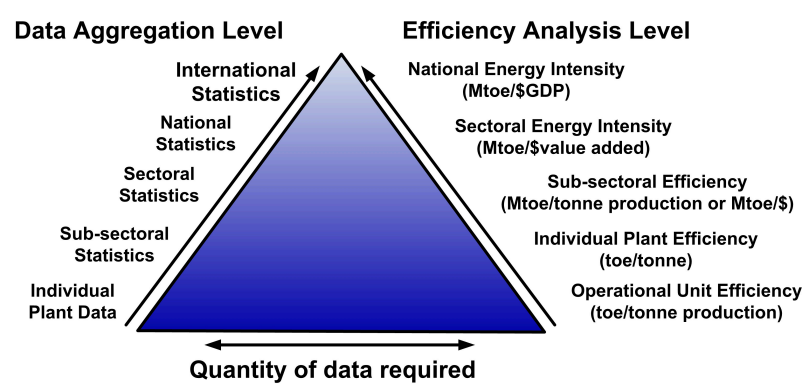

Figure 1: Energy efficiency indicator pyramid (Phylipsen et al., 1997)

Due to the variety of industrial processes and their complexity, the development of suitable energy performance indicators also depends on the purpose for which they will be applied e.g., indicators designed for a specific manufacturing sector. Special care has to be taken when defining any set of performance indicators. An indicator system should be complete regarding all important and relevant organisational objectives, and obviously every aspect of performance that is included must be quantifiable in order to be measurable. Finally, the indicator system has to be flexible to adapt it to changing environmental conditions or other fields of application (Zwingel, 1997).

Bunse et al. (2011) describe a number of energy performance measures that were identified by interviewing industry managers as part of the IMS2020 project. These include:

- Measures to identify inefficiencies within a plant's energy usage (consumption profiles);

- Measures to facilitate the tracking of changes and energy efficiency improvements;

- Energy efficiency measurement directly in monetary values to identify possible savings;

- Indicators for mapping energy usage for better understanding of input, output and measurement points for each industry specific manufacturing process.

\subsection{Analysis and Optimisation of Energy Consumption}

While monitoring energy use at the plant level will help to improve energy awareness in the company, such measures do not automatically suggest ways to reduce energy use. Significant improvements may require more sophisticated measurement, analysis and control techniques.

\subsubsection{Analysis of energy profiles}

Every factory site, manufacturing process, or single machine uses energy at a rate, which changes over time. This can be displayed as a power profile, which can be analysed using different timescales for different purposes. For example, at plant level such analysis may be useful to identify peak loads that would 
attract a surcharge from the energy utility company. In addition, analysis of cumulative energy profiles may inform investment decisions and operating policies at the plant or process level, such as the decision to purchase a new compressed air supply or an item of electrical equipment (Herrmann and Thiede, 2009).

Several software solutions have been proposed to support energy decisions by providing analysis of energy load profiles at different temporal levels, such as process control, production planning or enterprise asset management. Vijayaraghavan and Dornfeld (2010) propose a conceptual software-based approach for energy data analysis, which provides automated energy reasoning and decision support across multiple production levels and allows automated monitoring and analysis of energy consumption in manufacturing systems. They argue that such software must:

- Be capable of concurrent monitoring of energy use and technical process parameters,

- Adhere to data standards,

- Feature a scalable architecture to handle future increases in data volume, and

- Feature modular architecture to support analysis across different manufacturing scales.

Seem (2007) describes a robust method of rule-based statistical analysis of energy profiles to detect energy related events at the level of whole buildings. The method works by grouping data by day, then by pattern of energy use (such as average power, peak power, etc.) Analysis of energy data in this way provides a dataset representing normal performance from which 'energy events' may be detected as deviations from normal behaviour. The method might be applied to manufacturing in cases where sub-metering or individual machine data are not available. Where such data are available, a more detailed analysis of energy profiles can be carried out. Such an analysis could separate the energy used by technical building services (TBS), the machines, the factory environment and the energy and resource distribution network as described by Herrmann et al. (2011b).

\subsubsection{Energy Management Systems}

Information technology can help to manage and reduce the energy consumption in the factory. ISO 50001 (ISO, 2011) includes requirements for a programme of energy data collection such as the installation of automatic monitoring and targeting (AMT) systems, and this can be used to increase energy efficiency at different levels of a factory. Commercially available energy management systems (EMS) e.g., eSight M\&T / EMS (eSight Energy, 2012), EnergyCap (EnergyCAP, 2012) can collect energy data using one or more sub-meters and they can be used to identify opportunities for daily energy. They can be used with a range of sensor technologies to monitor energy carried by electricity and gas as well as other energy carriers. They can analyse these data to separate energy use resulting from production schedules from that which is driven by the weather. They can be used to target process, plant or site efficiency improvements and to display information at a range of levels from shop floor to stakeholder's level. However, these systems suffer from lack of standardisation and real-time automatic correlation of energy data across multiple production levels. Existing EMS have been shown to reduce energy use by $5 \%$ (Carbon Trust, 2008). Researchers have proposed energy information systems that go much further, allowing the optimization of manufacturing processes locally and globally by integrating energy management with manufacturing execution systems (Karnouskos et al., 2009, Vijayaraghavan and Dornfeld, 2010) and by applying systematic approach to the analysis of energy data (Herrmann and Thiede, 2009, Thiede et al., 2012). The first address the issue of data correlation and systems interoperability, but missing automatic data stream analysis algorithms and a decision support for a factory personnel. The systematic approach on the other hand uses historical data to model the dynamics between processes and all related material flows, and therefore decisions based on such models may be flawed if important process parameters have changed since the problem situation was modelled.

\section{Towards an Advanced Energy Management Framework}

In this paper, we propose a framework for advanced industrial energy management by continuously obtaining energyrelated information from any location of interest at the factory floor and combining it with enterprise wide information to enable system-wide optimization. The framework shown in Figure 2 is an extension of the generic approach presented by Vijayaraghavan and Dornfeld (2010). It includes the state-ofthe-art features of today's energy management systems such as a support of different communication interfaces, a set of energy related indicators with the addition of metrics to promote energy awareness in the context of productivity, CEP engine for event stream processing. The framework also incorporates features that go beyond state-of-the-art: energy data standard to mitigate the inconsistency and unreliability of much current practice with respect to energy data, a method for processing energy data in real-time to identify energy used by each production asset in each one of a set of defined operating states, and decision support for increasing energy efficiency and diagnosing failures at the production process level. The focus on the factory floor allows energy use to be linked to specific products, specific times of day and specific process states. Finally, the framework allows the calculation of performance metrics in real-time to support problem diagnosis and resolution and to communicate such information to decision makers using perceptually efficient visualisation. This is intended to reduce cognitive workload and improve situation awareness.

By using energy data to optimise production planning, one can schedule energy intensive tasks to avoid peak load or take advantage of energy from intermittent sources, such as solar energy. Similarly, production activities with heat requirements might be scheduled with another process that releases waste heat to take advantage of energy cascading (Groscurth et al., 1989, Hayajawam et al., 1999). 


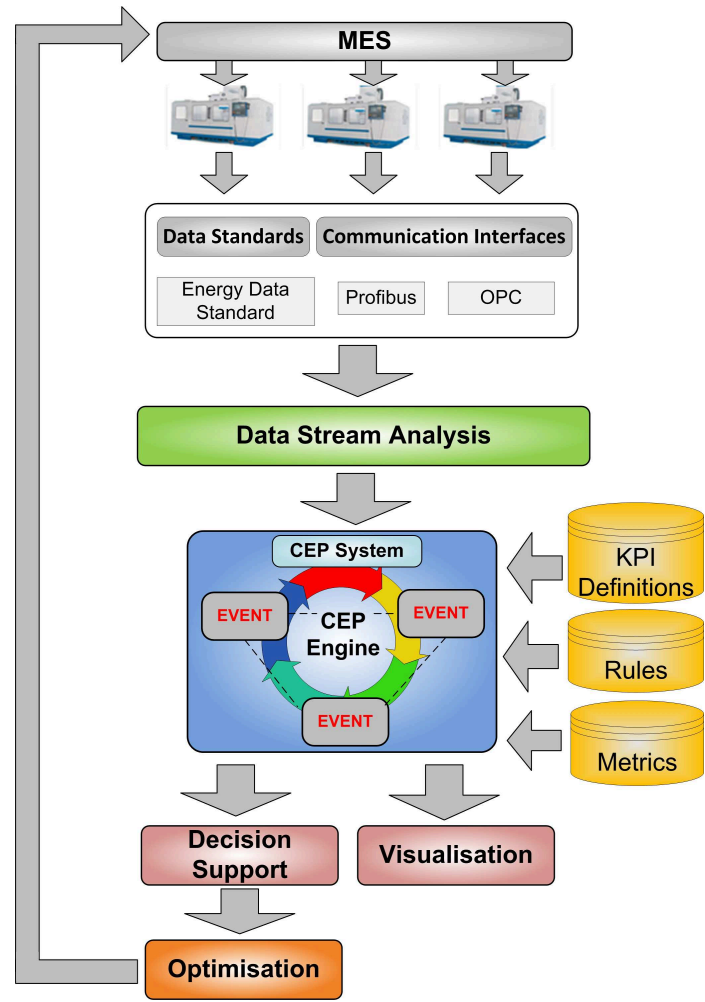

Figure 2: Proposed energy management framework

The model uses the following conceptual approach:

1. Energy use data are acquired in real-time from production assets,

2. The incoming data are analysed to produce a stream of 'events';

3. An event driven software tool (called the CEP engine see Section 4.4) processes the event stream using predefined logical rules in real-time and outputs a report or a suggested action;

4. Energy performance is calculated in real-time according to a set of energy related KPIs;

5. Energy performance is integrated into ERP/MES and displayed to workers for decision support.

\subsection{Data Standard Requirements}

Real-time energy monitoring requires an intensive exchange and correlation of data that are measured using a range of sensors, meters, industrial controllers, etc. Data interchange standards for energy are necessary to reduce the potential for error when converting between formats, and will increase the accuracy of the proposed framework. Improved data standards will also address current problems of unreliable energy data due to inconsistencies in documentation and poor data quality. Poor quality energy metadata can lead to differences between energy data structures and differences in notation for such fields as building addresses, electrical feeds or metering point numbers. If poor formatting means that a database server is not capable of processing the data, this can cause energy analyses to be corrupted by double counting, or critical energy data to be ignored
(Brown et al., 2010). Therefore, an energy data standard for manufacturing must (Brown et al., 2012a,b):

- Provide compatibility with historical data allowing performance comparisons and setting of realistic energy targets (ISO, 2011),

- Contain energy data in four main sections: time series data, metadata on accuracy and precision, supporting documentation (start, finish, sample rate, maintenance dates, performance issues, etc.) and energy data documentation (climate data, fuel types, etc.) (BSi, 2001, VDI, 2007),

- Store energy data documentation within the dataset, including data on the types of energy for which consumption data are stored e.g., calorific values for gas, appropriate conversion factors required to present energy data in standard units of $\mathrm{kWh}$,

- Allow zoning of data (i.e., data disaggregation) in relation to both building services and production to measure performance at different temporal levels and to avoid data duplication or double counting.

The data standard based on these requirements is used in the proposed framework.

\subsection{Data Stream Analysis}

Traditional industrial decision support systems collect data from multiple sources. These data are typically stored in a database and analysed off-line, allowing decision makers at each organisational level to identify problems, and propose solutions.

Analysis of continuous data streams allows more timely decisions but would result in very large files unless some form of data reduction is used. Data reduction would extract key events from data streams and analyse the timing and nature of them in order to derive energy performance information.

Recent studies (Herrmann et al., 2011a, Li et al., 2011, Pechmann and Schler, 2011) have shown that power signals monitored at a machine tool can be analysed to identify specific operations such as milling or drilling. Figure 3 shows a power profile for a milling process, including identifiable events such as machine start-up and shut-down, spindle acceleration, milling, surface finishing, drilling, and stand-by periods. Operating states can be classified thus:

1. Producing: production asset is adding value (e.g., energy used for the production),

2. Waiting: production asset is not adding value and is waiting for production (e.g., during short waiting for incoming parts or materials);

3. Idling: production asset is not adding value and is not waiting for production (e.g., during unscheduled events such as another machine's failure on the production line).

In principle, if one can recognise the different stages of any production process, one can create a database of reference patterns for that process. 


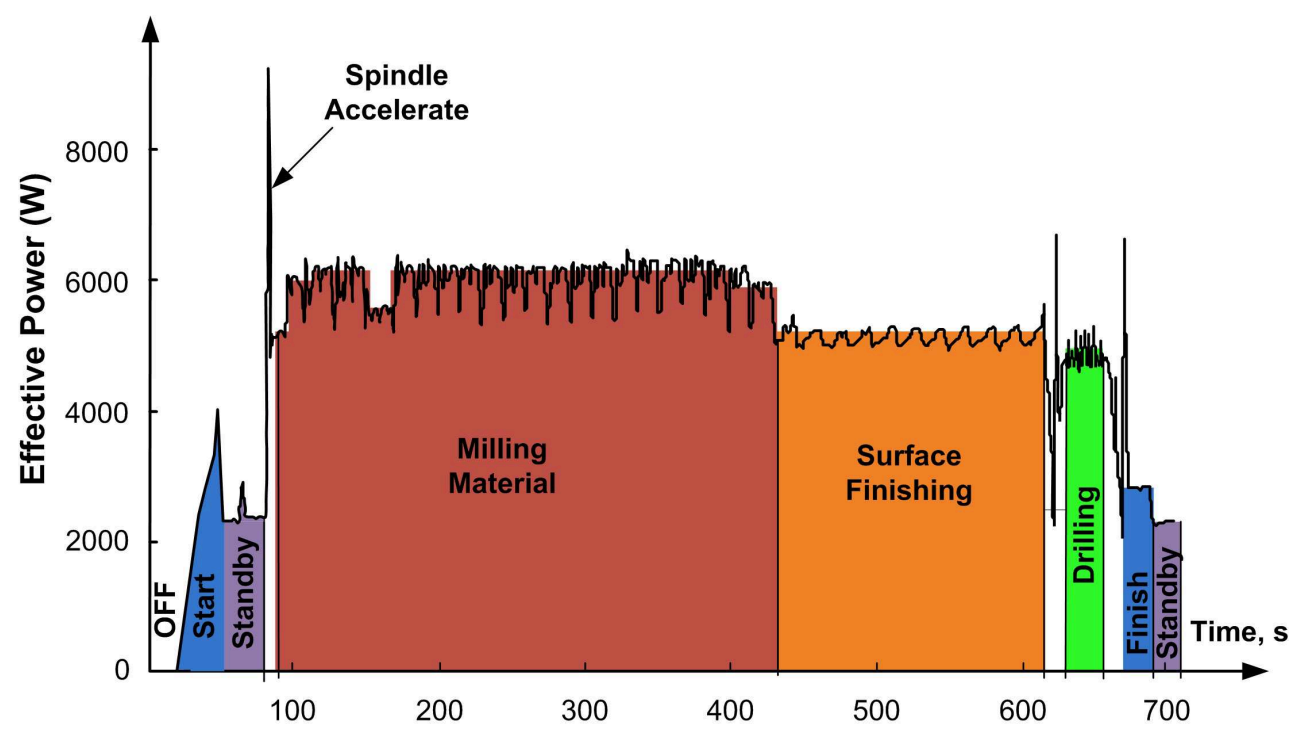

Figure 3: Power profile of a milling process

Pattern matching techniques based on 'dynamic time wrapping' or 'similarity subsequence matching' (Argyros and Ermopoulos, 2003, Assent et al., 2009, Sakurai et al., 2007, Wei et al., 2005) have been applied to monitor numerical streams and to find patterns that are similar to given reference signal. Chiotellis and Grismajer (2012) applied the SPRING algorithm (Sakurai et al., 2007) to the analysis of streams of manufacturing energy data, demonstrating real time automatic production stage recognition. Figure 4 shows a modification of their algorithm with real-time Z-normalisation of the input data stream, allowing manufacturing energy data to be processed and converted into the set of events related to the operational state of a machine. This modification is necessary since the original algorithm does not normalize the offset or amplitude of the matching data sequences (Sart et al., 2010). Therefore, it is assumed that the data sequences will naturally have the same offset and amplitude as the matching reference pattern. However, in real-world manufacturing applications that assumption is flawed and leads to poor detection of equipment operating states.

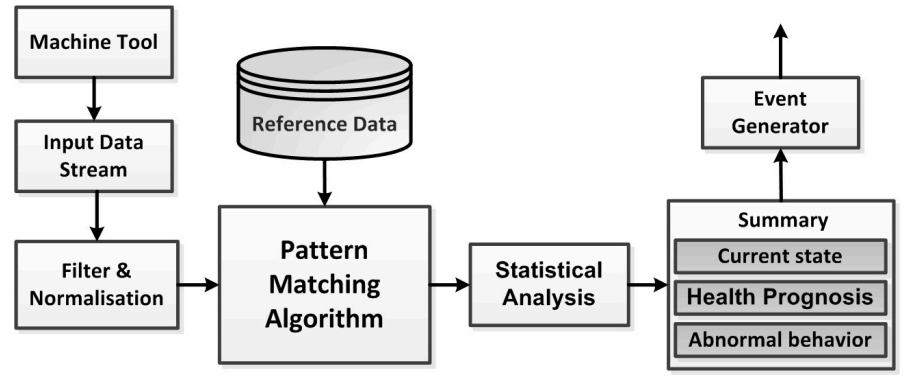

Figure 4: Data Stream Analysis (after Chiotellis and Grismajer, 2012)

Typical events might include machine failure, machine placed in standby mode, drilling complete, etc. These events can be used for further analysis and to derive energy perfor- mance in real-time. Figure 4 shows the data processing required for real-time energy data stream analysis. The incoming data stream is filtered and normalised. For electrical power we assume that the production process has been instrumented to collect data at a sample rate of between $2 \mathrm{~ms}$ and 1 minute. As shown by Chiotellis and Grismajer (2012), the choice of sample rate depends on the variability of the observed signal. Manufacturing equipment exhibits power signals that are highly dynamic compared to building services equipment (for example) so higher sample rates are used here than might be the case for building energy management systems. After the operating state of the production asset has been identified as a time series, the following indicators can be calculated: average power input, minimum and maximum power input, total energy used in each operating state, duration of each operating state, abnormal peaks and troughs, deviation of energy use from reference operating state. This approach can be extended for monitoring and analysing all energy carriers in real-time.

\subsection{Energy Performance Indicators}

Industrial energy management includes procedures for monitoring and targeting. Monitoring is necessary to derive knowledge of current energy use, whereas targeting compares energy data to set targets in order to identify management priorities for action. Energy related KPIs enable managers to react to changes in patterns of energy use.

Energy related KPIs should be independent of industry sector, application, timeframe, or energy carrier. The indicators presented in Table 1 are an overview of possible KPIs that have been chosen based on both the results of interviews with industry managers carried out by Bunse et al. (2011) as part of the IMS2020 project and discussions with industry partners with whom the authors are currently working.

Different sets of indicators can be identified depending on the required focus. The indicators presented in Table 1 focus 
Table 1: Selection of energy related KPIs

\begin{tabular}{|l|l|l|}
\hline Indicator name & Focus & Description \\
\hline Power & $\begin{array}{l}\text { Energy } \\
\text { consumption }\end{array}$ & Instantaneous or average power used by a process. \\
\hline $\begin{array}{l}\text { Energy } \\
\text { consumption }\end{array}$ & $\begin{array}{l}\text { Energy } \\
\text { consumption }\end{array}$ & Energy input into a process during a defined time period. \\
\hline $\begin{array}{l}\text { Specific energy } \\
\text { consumption }\end{array}$ & $\begin{array}{l}\text { Energy } \\
\text { consumption }\end{array}$ & $\begin{array}{l}\text { Energy consumption per item produced. Items can be defined as } \\
\text { a manufactured product or a monetary unit (revenue or profit). }\end{array}$ \\
\hline Energy costs & Energy costs & $\begin{array}{l}\text { Monetary cost of energy used including fixed and variable com- } \\
\text { ponents. }\end{array}$ \\
\hline $\begin{array}{l}\text { Specific energy } \\
\text { costs }\end{array}$ & Energy costs & Energy costs per manufactured product. \\
\hline Energy losses & $\begin{array}{l}\text { Energy } \\
\text { efficiency }\end{array}$ & $\begin{array}{l}\text { Energy use associated with non-value adding process steps or op- } \\
\text { erating states. }\end{array}$ \\
\hline Energy efficiency & $\begin{array}{l}\text { Energy } \\
\text { efficiency }\end{array}$ & $\begin{array}{l}\text { Output of an energy transformation process expressed as a per- } \\
\text { centage of the energy input to the process, hence energy conver- } \\
\text { sion efficiency (IEA, 2008a). }\end{array}$ \\
\hline
\end{tabular}

on energy consumption, costs, and efficiency. These indicators cover a range of different aspects of energy management.

\subsection{Complex Event Processing}

Complex event processing is widely used in information systems designed for highly dynamic business environments such as stock trading and business process management. It can also be used as part of an advanced energy management framework. CEP is defined as a set of tools and algorithms for analysing and processing a complex series of events (Luckham, 2001), where an event is defined as an instance of data that indicates that something has happened in an application environment. In manufacturing systems, examples of events may be a status variable exceeding a defined threshold level (such as maximum safe power level) or a machine state change (such as 'producing' to 'idling'). CEP can be used by software applications to derive real-time intelligence from data streams and make lowlatency decisions in response to changing conditions (Luckham, 2001, Wu et al., 2006).

Software systems using CEP aggregate data from various sources and apply predefined logical rules to identify patterns and trends that could be missed by a human observer. Such pattern matching gives organisations the ability to identify and anticipate opportunities presented by seemingly unrelated events. However, there are several difficulties when applying CEP in an industrial environment. The monitoring of the production process involves collecting data relating to a large number of process parameters from different parts of a network and hierarchical organisation, leading to a high volume of network traffic and problems with synchronisation of data. Data gaps due to synchronisation problems may lead to data corruption. Additionally, much of the acquired data might be unnecessary for the CEP process. The key to solving this problem is to use a distributed CEP system (i.e., processing is divided into embedded and server components) with the ability to filter out data that are unnecessary for analysis before transferring them over the network. By using timely data, the proposed system should allow better energy decisions than would be possible through offline analysis of historical data. A combination of data stream analysis and CEP allows the calculation of manufacturing system performance according to various energy KPIs, and the presentation of process status to provide real-time monitoring and targeting within the company. This approach provides new process improvement capabilities, for example the enhancement of preventive maintenance since excessive or unusual energy consumption might be an indication of a machine fault. CEP can allow production schedules to be dynamically optimised to reduce energy consumption.

\subsection{Visualisation}

Within manufacturing industry, the visualisation of energy use can be provided by supervisory control and data acquisition (SCADA) systems or MES software, although Bunse et al. (2011) have identified a gap between the potential of MES and enterprise resource planning systems in the area of industrial energy visualisation. Energy can be monitored and displayed in real-time and at different levels (from sub-process to organization), depending on the purpose. The display of energy data via a human-machine interface is intended to facilitate understanding of energy use patterns and trigger emergency action if needed. Since a poor understanding of energy use may lead to excessive waste, with financial and/or machine health implications, it is important that the display be clear and unambiguous. For this reason, colour graphics are often used in such displays and attention is paid to ergonomics so that users are presented with familiar graphical devices such as:

- XY plots of time series data to communicate changes over time e.g., energy load profile (Harris, 1999),

- Pie charts to compare relative values of indicators one to another and to the whole e.g., to communicate energy efficiency and losses (Harris, 1999, Preece and Keller, 1990), 


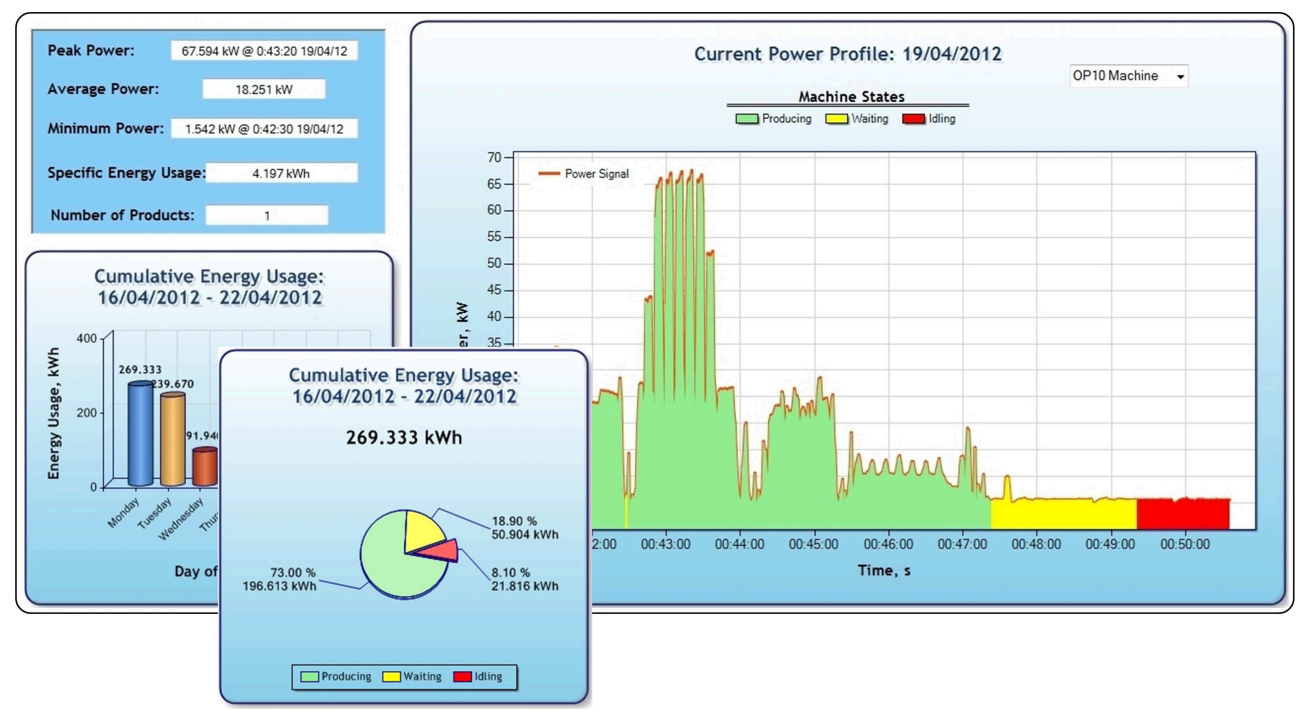

Figure 5: Example of the energy display for visualisation of electric energy consumption.

- Bar charts, which are an effective form of feedback of energy use (Arvola et al., 1993), to communicate and compare energy use over a specific time period of time,

- A needle on a dial to communicate instantaneous values,

- One or more digital readouts to display accurate unambiguous data e.g., peak power.

The design of the display should be chosen to reflect the energy management priorities of the organisation, at the level at which energy is being monitored. At the operational level energy managers are concerned with the technological performance of a process including the energy used by the process, the energy state of the equipment, energy use peaks and troughs, etc. An example of a display for enhancing energy awareness on the factory floor is shown in Figure 5. To reflect the nature of the particular process the XY plot displays an energy load profile in real-time. The different colours used for parts of the energy profile represent energy used during the three main energy states of the process, which are: producing (energy use during value-adding process steps), waiting (necessary energy use during non-value adding process steps) and idling (unnecessary energy use during non-value adding process steps). Pie charts are used to show the proportions of energy used by the equipment in different states on a particular day, week, month, etc. Total energy use over a specific time period is represented as a bar chart. The digital readouts display maximum, mean and minimum power values and a 'specific energy use' indicator which measures energy in $\mathrm{kWh}$ per unit of production.

\section{Case Study}

At the time of writing, the framework described is being deployed via a prototype information system in a machining line
(13 multi-operation machines) of a major European automotive manufacturer. Production machines are arranged in a typical U-shaped line. There are also some energy-using ancillary systems including cutting fluid recirculation, compressed air, heating and ventilation, etc. An preliminary factory energy survey has shown that one of the main energy losses in the factory (about 20-30\%) relates to production machine idling. Idling energy losses are usually caused by inefficient operation by line personal. This is the reason for the design and evaluation of the prototype energy management system described above. It should be noted that the manufacturer uses a manufacturing execution system (MES), which provides real-time process monitoring and production scheduling; however, it does not monitor energy. The input and output MES interfaces are summarized in Figure 6.

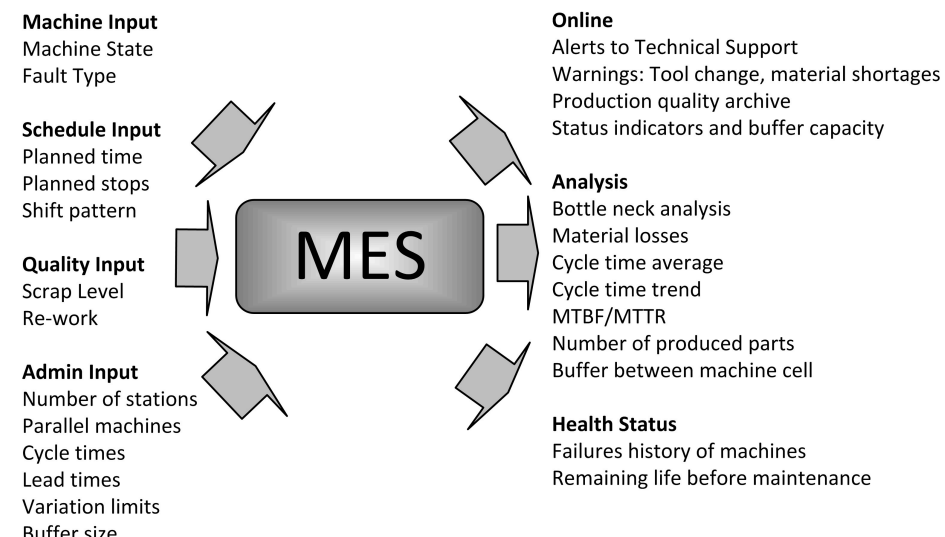

Figure 6: MES interface specifications

The prototype energy management system is designed to acquire and process the energy data stream acquired from any industrial asset that uses energy, whether it is a value adding device such as a machine tool, a device supplying technical building services (TBS) such as a chiller unit or a piece of periphery 
Table 2: Evaluation of state recognition by pattern matching

\begin{tabular}{|l|l|l|l|}
\hline Energetic state parameter & Prototype system & MES & Comment \\
\hline 1. Average time in producing state & $911 \mathrm{~s}$ & $889 \mathrm{~s}$ & $2.5 \%$ difference \\
\hline 2. Average time in waiting state & $189 \mathrm{~s}$ & $193 \mathrm{~s}$ & $2.1 \%$ difference \\
\hline 3. Average time in idling state & $16360 \mathrm{~s}$ & $15574 \mathrm{~s}$ & $2.5 \%$ difference \\
\hline 4. Average energy used during idling & $370 \mathrm{MWh} /$ year & N/A & $23 \%$ of annual energy consumption \\
\hline
\end{tabular}

equipment such as a coolant pump. The software in the system consists of two parts: the client, which is running on an industrial PC near the production assets and the server, which is running on the server computer. The industrial PC used for the case study is a Beckhoff CX1030. It is equipped with I/O modules that enable measurement of all relevant electrical supply data (current, voltage and power factor in each phase) at up to $10 \mathrm{~ms}$ data resolution. Voltage is measured using a direct connection and the current in each phase is measured using current transformers.

Energy data are calculated from the measured parameters and streamed at a frequency of $1 \mathrm{~Hz}$ from each monitored asset.The client part of the software uses a modified version of the SPRING algorithm to identify repeated patterns in this stream. Each pattern represents a specific operating state of the asset, such as 'producing', 'waiting', and 'idling'. The energy consumption and duration of each energetic state can be expected to depend on the type of machine. In this case and following discussions with factory experts, the following energetic states were defined: producing $(8-30 \mathrm{~kW})$, waiting $(3-8 \mathrm{~kW})$ and idling (0.6-1 kW).

Table 2 shows a comparison of these states as identified by the MES and as identified by the prototype system over a period of a week. The comparison was made to validate the choice of energy patterns used when training the software. As well as identifying machine states, the algorithm can be trained to identify the energy profiles corresponding to different products or parts, therefore determine specific energy consumption by product type. The client part also detects and logs power peaks and drops. The processed data are then passed to the server part of the software that provides visualisation of energy data to machine operators. Figure 5 depicts the user interface of the prototype. Production process schedule optimisation is provided through MES interface.

The software framework was implemented using the Microsoft StreamInsight complex event processing platform (Microsoft, 2012).The overall cost of the system including the equipment and installation costs is less than $€ 7000$.

\section{Discussion}

The proposed framework provides number of features that goes beyond state-of-the-art, such as energy data standard, algorithm for real-time data streams analysis and CEP engine that provides decision support information for increasing energy efficiency and diagnosing failures at the production process level. This allows the workforce to be more energy aware and to make energy efficient decisions. In the case company, machine operators are empowered with the authority to shut down machines if they believe capacity will not be needed for a significant time and to re-schedule machining operations to make best use of resources and time.

Interviews were conducted with several experts representing the company such as a project manager, a head of department, a production technician, a shift leader and line operators. In the interviews it became evident that there is a need for such IS. For example, a project manager explained that "real-time energy information needs to be available for all personnel in the plant, like operators and production technicians. This information should be easy to understand and to access, allowing to make decision, such as turning on and off equipment". Similarly, a production technician stated that "available monthly energy measurements per department level do not allow identifying energy saving opportunities". Shift leader and operators are highly motivated to reduce energy use, however interviewees explained that existing MES "does not estimate on/off times for a machine, predicting machine availability is required". All interviewees confirmed that the prototype system help to identify inefficiencies within lines energy use, optimise production process and detect equipment faults. To date, the prototype system has been tested but not evaluated in the factory since it is intended to support a new machining line to be installed in the near future.

Much of the functionality discussed above could be realised by combining production systems with a sophisticated MES, however the energy management system described could be used in organisation that do not use an MES in which case it would provide the following advantages:

- Low cost. The system requires minimum setting up to monitor energy and train using expert knowledge,

- Detection of states of any production equipment including technical building services and ancillary systems. These would be unlikely to be connected to the MES even if one was used,

- Detection of degraded energy profile or extreme energy event could facilitate the use of energy as a process control variable for predictive maintenance (prognostic) purposes,

- Energy profile analysis supports fault diagnosis,

- Generation of detailed energy profiles for each product may assist production planning, energy accounting and carbon footprinting. 
Limitations of the proposed framework are the requirement for expert knowledge during training and the fact that the system will produce positive results only if workers and energy managers are motivated to make energy efficient decisions prompted by the information the system can provide.

\section{Conclusions}

Manufacturers are facing a number of challenges including rising energy costs and increasingly strict emissions legislation that mean that they can no longer regard energy as a fixed and relatively small operational expense. For many manufacturers, energy must be monitored more closely and controlled in realtime. Energy management is becoming a key skill in the manufacturing operations of many companies. Existing solutions for measurement, analysis and control of energy do not address all the requirements of energy management at the organisation, factory or process level because they do not adequately develop in the workforce an awareness of the energy used in their business.

This paper has presented a new framework for advanced energy management that provides information about the energy performance of a production system in real-time for decision makers at all production levels, supporting effective strategic and operational decisions in the company. The framework supports the standardization of all measured energy data for future analysis and visualization. This will also allow the decisionsupport elements of the production system (such as enterprise software) to utilize energy consumption as an optimization parameter in a real-time and closed-loop fashion. A set of basic energy performance measures that can be used for calculation and prediction of manufacturing system behaviour based on enhanced knowledge of its energy characteristics was presented. The framework focuses not only on acquiring data, but also on data processing and correlation so that one can obtain meaningful information from the factory floor. The paper has described advanced techniques for real-time analysis of data streams, such as pattern matching algorithms, which in combination with complex event processing allows real-time analysis of incoming data. Finally, the paper indicates the importance of visualisation of energy data. Future work will focus on the development of a factory-wide energy consumption model, which will include production processes and technical building services; and an exploration of the energy saving potential of this.

\section{Acknowledgments}

The authors would like to thank the European Commission and the partners of the European FP7 project "Knowledge, Awareness and Prediction of Man, Machine, Material and Method in Manufacturing" (www . kap-pro ject . eu, NMPICT-FoF-2010-260111) for their support.

\section{References}

Ahmad, M. M., Dhafr, N., 2002. Establishing and improving manufacturing performance measures. Robotics and Computer-Integrated Manufacturing 18 (3-4), $171-176$.
Argyros, T., Ermopoulos, C., November 2003. Efficient subsequence matching in time series databases under time and amplitude transformations. In: Proceedings of Third IEEE International Conference on Data Mining (ICDM 2003). IEEE Computer Society.

Arvola, A., Uutela, A., Anttila, U., 1993. Billing feedback as means to encourage household electricity conservation: A field experiment in Helsinki. In Proceedings of the 1993 summer study of the European Council for an energy efficient economy, 7585.

Assent, I., Wichterich, M., Krieger, R., Kremer, H., Seidl, T., August 2009. Anticipatory dtw for efficient similarity search in time series databases. In: Proceedings of 35th International Conference on Very Large Data Bases (VLDB 2009). Vol. 2. VLDB Endowment, Lyon, France, pp. 826-837.

Brown, N., Greenough, R., Vikhorev, K., 2012a. Some aspects of a framework for energy data. In: Proceedings of 7th international conference on improving energy efficiency in commercial buildings (IEECB 2012). Frankfurt.

Brown, N., Greenough, R., Vikhorev, K., Khattak, S., 2012b. Precursors to using energy data as a manufacturing process variable. In: Proceedings of 6 th intl. conf. on Digital Ecosystem Technologies (IEEE-DEST-2012). Campione dItalia.

Brown, N., Wright, A., Shukla, A., Stuart, G., 2010. Longitudinal analysis of energy metering data from non-domestic buildings. Building Research and Information 38 (1), 80-91.

BSi, August 2001. BS EN 60255-24:2001, IEC 60255-24:2001 Electrical relays. Common format for transient data exchange (COMTRADE) for power systems.

BSi, 2009. EN 16001:2009 Energy management systems - Requirements with guidance for use. Brussels.

Bunse, K., Vodicka, M., Schönsleben, P., Brühart, M., Ernst, F. O., 2011. Integrating energy efficiency performance in production management - gap analysis between industrial needs and scientific literature. Journal of Cleaner Production 19 (6-7), $667-679$.

Carbon Trust, 2008. Automatic monitoring and targeting equipment: A guide to equipment eligible for Enhanced Capital Allowances. Report number ECA756, available from www.carbontrust.co.uk, accessed 4th July 2012.

Chiotellis, S., Grismajer, M., 2012. Analysis of electrical power data streams in manufacturing. In: Proceedings of the 19th CIRP Conference on Life Cycle Engineering. Springer Berlin Heidelberg, UC Berkeley, CA USA, pp. 533-538.

Darby, S., 2006. The effectiveness of feedbackon energy consumption: A review for defra of the literature on metering, billing and direct displays. Tech. rep., Environmental ChangeInstitute,University of Oxford.

EnergyCAP, 2012. EnergyCAP Energy Management System. Retrieved November 19, 2012, from http://www.energycap.com/.

eSight Energy, 2012. eSight Energy Monitoring and Targeting / Energy Management System. Retrieved November 19, 2012, from http://www.esightenergy.com/.

Evans, S., Bergendahl, M. N., Gregory, M., Ryan, C., 2009. Towards a Sustainable Industrial System: With Recommendations for Education, Research, Industry and Policy. University of Cambridge, Institute for Manufacturing, http://www.ifm.eng.cam.ac.uk/sis/ industrial_sustainability_report.pdf.

Greenwood, D. E., 1999. Action Research - From Practice to Writing in an International Action Research Development Program. John Benjamins Publishing Company, Amsterdam/Philadelphia.

Groscurth, H. M., Kummel, R., Gool, W. V., 1989. Thermodynamic limits to energy optimization. Energy 14 (5), 241 - 258.

Hargreaves, T., Nye, M., Burgess, J., 2010. Making energy visible: A qualitative field study of how householders interact with feedback from smart energy monitors. Energy Policy 38 (10), 6111 - 6119.

Harris, R., 1999. Information graphics: A comprehensive illustrated reference. Oxford University Press, USA.

Hart, G., December 1992. Nonintrusive appliance load monitoring. Proceedings of the IEEE 80 (12), $1870-1891$.

Hayajawam, N., Wakazono, Y., Kato, T., Suzuoki, Y., Kaya, Y., 1999. Minimizing energy consumption in industries by cascade use of waste energy. Energy Conversion, IEEE Transactions on 14 (3), 795 -801.

Herrmann, C., Heinemann, T., Thiede, S., May 2nd - 4th 2011a. Synergies from process and energy oriented process chain simulation a case study from the aluminium die casting industry. In: Proceedings of the 18th CIRP International Conference on Life Cycle Engineering. Technische Universitt Braunschweig, Springer-Verlag Berlin Heidelberg, Braunschweig, Germany. 
Herrmann, C., Suh, S.-H., Bogdanski, G., Zein, A., Cha, J.-M., Um, J., Jeong, S., Guzman, A., May 2nd - 4th 2011b. Context-aware analysis approach to enhance industrial smart metering. In: Proceedings of the 18th CIRP International Conference on Life Cycle Engineering. Technische Universitt Braunschweig, Springer-Verlag Berlin Heidelberg, Braunschweig, Germany.

Herrmann, C., Thiede, S., 2009. Process chain simulation to foster energy efficiency in manufacturing. CIRP Journal of Manufacturing Science and Technology 1 (4), $221-229$.

IEA, 2007. Tracking Industrial Energy Efficiency and CO2 Emissions. Tech. rep., The International Energy Agency (IEA), http: //www.iea.org/ textbase/nppdf/free/2007/tracking_emissions.pdf.

IEA, 2008a. Assessing Measures of Energy Efficiency Performance and Their Application in Industry. Tech. rep., The International Energy Agency (IEA), http://www.iea.org/papers/2008/JPRG_ Info_Paper.pdf.

IEA, 2008b. Worldwide Trends in Energy Use and Efficiency - Key Insights from IEA Indicator Analysis. Tech. rep., The International Energy Agency (IEA), http://www.iea.org/Papers/2008/Indicators 2008 .pdf.

IEA, 2010. Key world energy statistics 2010. Tech. rep., The International Energy Agency (IEA), Paris, http://www.iea.org/textbase/ nppdf/free/2010/key_stats_2010.pdf.

ISO, 2008. ISO 9001:2008 Quality management systems - Requirements. International Organization for Standardization (ISO).

ISO, 2011. ISO 50001:2011 Energy Management Systems Standard - Requirements with guidance for use. International Organization for Standardization (ISO).

Kannan, R., Boie, W., 2003. Energy management practices in smecase study of a bakery in germany. Energy Conversion and Management 44 (6), 945 959

Kara, S., Bogdanski, G., Li, W., May 2nd - 4th 2011. Electricity metering and monitoring in manufacturing systems. In: Proceedings of the 18th CIRP International Conference on Life Cycle Engineering. Technische Universitt Braunschweig, Springer-Verlag Berlin Heidelberg, Braunschweig, Germany.

Karnouskos, S., Colombo, A., Lastra, J., Popescu, C., june 2009. Towards the energy efficient future factory. In: 7th IEEE International Conference on Industrial Informatics, 2009. INDIN 2009. pp. $367-371$.

Lertlakkhanakul, J., Yoon, S., Choi, J., 2010. Developing a building energy management bframework based on ubiquitous sensor networks. Indoor and Built Environment 19 (1), 192-201.

Li, W., Zein, A., Kara, S., Herrmann, C., May 2nd - 4th 2011. An investigation into fixed energy consumption of machine tools. In: Proceedings of the 18th CIRP International Conference on Life Cycle Engineering. Technische Universitt Braunschweig, Springer-Verlag Berlin Heidelberg, Braunschweig, Germany.

Luckham, D. C., 2001. The Power of Events: An Introduction to Complex Event Processing in Distributed Enterprise Systems. Addison-Wesley Longman Publishing Co., Boston, MA, USA.

Meyers, R. J., Williams, E. D., Matthews, H. S., 2010. Scoping the potential of monitoring and control technologies to reduce energy use in homes. Energy and Buildings 42 (5), $563-569$.

Microsoft, 2012. Microsoft StreamInsight. http://msdn.microsoft. com/en-us/library/ee362541.aspx.

MTConnect, 2010. MTConnect Standard. Tech. rep., MTConnect Institute, William Sobel, http: //mtconnect.org.

Patel, S. N., Robertson, T., Kientz, J. A., Reynolds, M. S., Abowd, G. D., 2007. At the flick of a switch: detecting and classifying unique electrical events on the residential power line. In: Proceedings of the 9th international conference on Ubiquitous computing. UbiComp '07. Springer-Verlag, Berlin, Heidelberg, pp. 271-288.

Pechmann, A., Schler, I., May 2nd - 4th 2011. Optimizing energy costs by intelligent production scheduling. In: Proceedings of the 18th CIRP International Conference on Life Cycle Engineering. Technische Universitt Braunschweig, Springer-Verlag Berlin Heidelberg, Braunschweig, Germany.

Phylipsen, G. J. M., Blok, K., Worrell, E., 1997. International comparisons of energy efficiency-methodologies for the manufacturing industry. Energy Policy 25 (7-9), $715-725$.

Preece, J., Keller, L., 1990. Human-computer interaction: selected readings : a reader. Prentice Hall in association with Open University.
Sakurai, Y., Faloutsos, C., Yamamuro, M., april 2007. Stream monitoring under the time warping distance. In: Proceedings of IEEE 23rd International Conference on Data Engineering, 2007. ICDE 2007. pp. 1046 -1055.

Sart, D., Mueen, A., Najjar, W., Keogh, E., Niennattrakul, V., December 2010. Accelerating dynamic time warping subsequence search with gpus and fpgas. In: Proceedings of the IEEE 10th International Conference on Data Mining (ICDM). IEEE Computer Society, Washington, DC, USA, pp. 1001 -1006 .

Seem, J. E., 2007. Using intelligent data analysis to detect abnormal energy consumption in buildings. Energy and Buildings 39 (1), 52 - 58.

Thiede, S., Bogdanski, G., Herrmann, C., 2012. A systematic method for increasing the energy and resource efficiency in manufacturing companies. Procedia CIRP 2 (0), $28-33$.

VDI, 2007. VDI 4602 Blatt 1:2007 Energy Management Standard: Energy Management Terms, definitions. Tech. rep., VDI-Society Energy and Environment.

Vijayaraghavan, A., Dornfeld, D., 2010. Automated energy monitoring of machine tools. CIRP Annals - Manufacturing Technology 59 (1), 21-24.

Wei, L., Keogh, E., Van Herle, H., Mafra-Neto, A., November 2005. Atomic wedgie: efficient query filtering for streaming time series. In: Proceedings of Fifth IEEE International Conference on Data Mining (ICDM05). pp. 490497.

WRI, 2009. GHG Protocol Scope 3 Standard and GHG Protocol Product Standard. World Resources Institute and the World Business Council for Sustainable.

Wu, E., Diao, Y., Rizvi, S., 2006. High-performance complex event processing over streams. In: Proceedings of the 2006 ACM SIGMOD international conference on Management of data (SIGMOD '06). New York, USA.

Yin, R., 2008. Case Study Research: Design and Methods, fourth ed. Sage Publications, Inc, Thousand Oaks, Calif.

Zwingel, T., 1997. Einsatzmöglichkeiten und Grenzen von Kennzahlen und Kennzahlensystemen im Rahmen eines ökologischen Controllingkonzepts. Verlag V. Florentz, München. 